\title{
The Challenge of Coming to Terms with the Use of a New Digital Assistive Device: A Case Study of Two Persons with Mild Dementia
}

\author{
Eva Karlsson ${ }^{*}, 1$, Karin Axelsson ${ }^{1}$, Karin Zingmark ${ }^{2}$ and Stefan Sävenstedt ${ }^{1}$ \\ ${ }^{I}$ Department of Health Science, Luleå University of Technology, Sweden \\ ${ }^{2}$ Department of Research and Development, the County Council of Norrbotten, Sweden
}

\begin{abstract}
There is an increased interest in supporting persons with dementia with technical services in daily life. The aim of this case study was to explore the complex issues involved in the process from a user driven development to the acceptance and usage of a new digital assistive device for persons with mild dementia. Even though it was developed in a user driven process and personalized to meet their individual needs they rarely used it. To deepening the understanding of this disparity between actual usage and perceived usefulness, the participants were studied whilst performing daily life activities through participant observations and interviews. Their partners were interviewed two years after the first observations to clarify the change in needs over time. The results show that the participant needs encompassed occupation, safety, social interaction, and memory support together with the receipt of general support. The overriding requirement for both participants was a need to maintain their self-image. When the digital assistive device did not correspond with the participants' expectations or view of themselves, their interest in using it faded, since the digital assistive device failed to support their self-image. The acceptance of a digital assistive device by a person with dementia is a process that begins with identifying and personalizing the functions of the device according to individual needs, and then supporting the usage and the gradual integration of the device into daily life. During this process, the person's selfimage must be taken into consideration and supported.
\end{abstract}

Keywords: Digital assistive device, dementia, needs, user-driven development, participant observations, case study, selfimage.

\section{INTRODUCTION}

There is an increased interest in supporting persons with dementia in their daily life by different kinds of technical services to improve their safety, autonomy and their quality of life, as well as improving their ability to live independently [1]. This development also reflects an interest in person-centred care, which can be summarized as a standpoint where personhood in persons with dementia is regarded as concealed but not lost, that the personhood should be acknowledge at all aspects of care and interpretation of behavior should take its starting point from the view of the person with dementia and that shared decision making should be offered [2]. Furthermore, both care and surroundings should be personalized, and the relationship with others should be prioritized. Person-centred care is a way to promote a continuing of self and normality, the possibility to maintain previous meaningful activities and the environment personalized [3].

In the provision of person-centred support, it is important to understand the uniqueness of each person and their personal needs, designing new digital assistive devices in a user-driven development [4]. The concept of need can be viewed from different perspectives depending on the researcher's point of view. In biological science, the concern is on physiological or somatic needs related to survival and

*Address correspondence to this author at the Lulea University of Technology, Department of Health Science, 97187 Lulea, Sweden; Tel: +467020012 82; E-mail: eva.1.karlsson@ltu.se health. Social scientists, in contrast, discuss needs in a context of social interaction, culture or international politics [5]. Schölzel-Dorenbos, Meeuwsen and Olde Rickert [6] divide needs into subjective, objective, personal and societal needs, and Maslow [7] claims that there is a hierarchy of needs in which basic existential needs must be satisfied before needs on higher levels. Psychologists discuss human needs on higher levels in terms of the need for self-esteem and having a sense of self [5]. In a holistic assessment, needs are perceived in relation to one another and the context in which the person is living. There is also a distinction between needs, and desires and satisfiers, where needs are seen as universal, and desires and satisfiers are spatially, temporally and personally determined [5].

Although there is increased interest in the participatory development of information technology based digital assistive devices to meet the needs of persons with dementia, knowledge of how to conduct this process is sparse [8], even if there are examples of studies where persons with dementia has been directly involved in the development $[9,10]$. In addition, more information is required about the factors that influence the acceptance of digital assistive devices among persons with dementia.

The uniqueness of an individual is related to that person's personhood. Kitwood [11] defines personhood as striving to be a person, a strive that should be supported by promoting what is unique in every person. He also argues that this approach is a prerequisite to achieving a real interaction between persons, which is in it self a prerequisite to 
understanding a person's needs. According to Sabat [12], selfhood can be kept intact by being viewed as a competent person despite the disease. A person with dementia viewed from that perspective can constructively participate in a userdriven process of developing the support that is appropriate for their needs $c f$. [13].

Research on meeting the needs of persons with dementia has identified key areas as the need: for an early diagnosis, to be heard, for information and knowledge, to feel safe, to promote their health and for emotional and cognitive support [14]. Other frequently reported needs are for daytime activities and social interaction [15-17]. To be accepted as they are, to find adequate coping strategies and to coming to terms with their situation are other identified needs [18]. This research often describes needs on higher levels and makes no clear distinction between needs, desires and satisfiers $c f$. [5].

An example of a digital assistive device intended to meet some of the needs of people with dementia was developed in the CoGKNOw project [19]. The device consists of two parts, one stationary and the other mobile, which integrate functions to support memory, social contact, daily activities, and intended to enhance the feeling of safety; the devices could also be adjusted to meet the needs of the individuals using them. The prototype was tested and evaluated for a total of 42 persons with dementia in three iterations and in three European countries. In this study, the experiences from the second iteration of the evaluation were used. In the second test, both general and individual functions were tested over a two-week long period. The user-driven process of developing the pilot devices used in the project involved the participants and their carers, and was based on assessing needs that were then transformed into adjusted functions in the device. Although the need assessment was thorough and the responses of the person with dementia and the carer concerning the usability and the different functions available on the tested device were positive, the devices were seldom used. On the basis of these experiences, it was decided to make a separate case study to deepen the understanding of how the performance of the activities involved in the daily life of persons with dementia could provide additional knowledge about this disparity between actual usage and the perceived usefulness of an assistive device.

\section{AIM}

The aim of this case study was to explore the complex issues involved in the process from a user-driven development to the acceptance and usage of a new digital assistive device for persons with mild dementia.

\section{METHOD}

Within the framework of the COGKNOW project [19] a qualitative case study was performed $c f$. [20] where two persons with mild dementia were the cases. The case methodology was chosen in order to provide the possibility to study complex situations and get a deeper understanding while taking the context of the situation into account [21]. It provided a powerful adjunct for exploring particular aspects of the phenomena under investigation [22].

\section{Subjects}

The participants in the case study, Alice and Sven, (fictitious names), were chosen amongst the participants in the Swedish trial of the second iteration of the CoGKNOw project. The bases for selection were that their gender and ages differed and that their social contexts were diverse. Both Alice and Sven also had a good ability to communicate. The inclusion criteria for the subjects in the COGKNOW project were mild dementia, defined as a MMSE score [23] of between 17 and 25 out of 30 and that they were living in their own home.

\section{Data Collection}

\section{Procedure}

Data were collected in three phases over a time period of 24 months using a method for participant observation [24] combined with semi structured interviews performed in direct connection with the observations $c f .[25,26]$ and as separate interviews with the partners. The MMSE score [23] was measured by the first author at the beginning of the case study. The first phase included making unstructured participant observations [24] during a time span of six months in connection to the second field test of the COGKNOW project (ref). The intention was to gain an understanding of each of the participant's context of living $c f$. [27]. The second phase followed directly after the first and included selected participant observations [24] and interviews with Alice and Sven while they carried out their daily life activities. The third phase took place 18 months after the first phase, and included interviews with Alice and Sven's partners to obtain information related to the changes that had taken place over time.

\section{Observations of and Interviews with the Person with Dementia}

During the first phase the first author met the participants regularly, visiting their homes and doing activities together. During these meetings unstructured observations [24] were performed with the purpose to identify important areas in daily life suitable for selected participant observations [24] in the second phase. These areas where chosen in consultation with their partners and included the way in which Alice and Sven conducted the activity under consideration, their behavior when they got insecure and what strategies they used in case of insecurity. The researcher used a digital memo recorder to record important prompts to ensure that questions about important observations would not be forgotten in the subsequent interview. The documentation of the observations was carried out as reflected in the notes made during and directly after the observations and were completed when the researcher got back to the office. These field notes described what happened during the observation in detail, including the participant's behavior and the researcher's own reflections cf. [24]. After each observation, a tape recorded interview was conducted with the participant centred on the notes made during the observation. (Table $\mathbf{1}$ ).

\section{Interviews with the Partner}

An open interview was conducted 18 months after the first phase of data collection with Alice's and Sven's partner, 
Table 1. Overview of Selected Participant Observations Studied, Number of Occasions and Duration in Hours

\begin{tabular}{|c|c|c|c|c|c|c|}
\hline Activity Studied & Alice & Occasions & Duration & Sven & Occasions & Duration \\
\hline Cleaning the house & $\mathrm{X}$ & 1 & 4 & & & \\
\hline Preparing a simpler meal & $\mathrm{X}$ & 1 & 3 & & & \\
\hline Doing the laundry & $\mathrm{X}$ & 1 & 3 & & & \\
\hline Maintenance of the house & & & & $\mathrm{X}$ & 1 & 4 \\
\hline Visiting a day care centre & & & & $\mathrm{X}$ & 1 & 3 \\
\hline Walks in the vicinity of the home & $\mathrm{X}$ & 1 & 2 & $\mathrm{X}$ & 2 & 6 \\
\hline $\begin{array}{l}\text { Visiting a familiar environment, including making a simple purchase in } \\
\text { a store and eating lunch at a restaurant }\end{array}$ & $\mathrm{X}$ & 1 & 5 & $\mathrm{X}$ & 2 & 9 \\
\hline Visiting a familiar environment, including travelling by public transport & $\mathrm{X}$ & 1 & 4 & & & \\
\hline $\begin{array}{l}\text { Staying in a less familiar environment, including making a simple } \\
\text { purchase in a store }\end{array}$ & $\mathrm{X}$ & 1 & 6 & & & \\
\hline Total hours of observations & & 7 & 27 & & 6 & 22 \\
\hline
\end{tabular}

focusing on whether and how the progress of the disease had affected Alice's and Sven's ability to perform daily activities. The interview covered areas in which needs had already been identified in the observations and interviews with Alice and Sven.

\section{Data from the COGKNOW Project}

The results obtained previously that were directly related to Alice and Sven were extracted from the evaluation in the second test in the COGKNOW project. These were grouped according to areas of need, the personalized functions offered by the device, and their responses to the usefulness of the functions (Table 2). In this analysis, the concept of needs was not distinguished from desires and satisfiers as discussed in the introduction [5].

\section{Data Analysis}

The data was initially analysed separately for each participant and each phase of the data collection, using a method for qualitative content analysis $c f$. [28]. The text describing all observations and interviews was merged to form one text, making sure that all text relating to the same activity was kept together. The merged text was then read through several times to gain a deeper understanding of the content. Thereafter, the text units were identified and condensed. Units with similar content were merged, grouped, and categorized $c f$. [29]. Finally, a reflection on the complexity of the issues involved in using a new digital assistive device was made. This reflection was based on the data obtained from the results of the analysis of the performance of activities in daily life together with the experiences that had been reported when testing the device with Alice and Sven in the second iteration of test in the COGKNOW project.

\section{Ethical Considerations}

The study was carried out within the framework of the COGKNOW project, which was approved by the Regional Ethical Review Board for research in northern Sweden (2054-2006). All participants and their partners gave their written informed consent to their participation in the study.

\section{RESULTS}

The results are described separately for each participant and are grouped according to each person's needs.

\section{Alice's Story}

Alice was about 60 years old when she was included in the COGKNOW project and had received her diagnosis of dementia two years earlier. Her MMSE score [23] was 17 of 30 points. She had retired five years before the study started because of she had problems with her back. She lived with her husband in the house they had been living in for thirty years. Her partner had gradually taken over more of the responsibility for the household duties. He was working and Alice was alone in the home during working hours. She spent her days doing cleaning, laundry or other household duties. Alice and her partner used to have an extensive social life that gradually decreased after Alice became ill with dementia. Their daughters lived nearby and visited their parents quite often.

\section{Testing the COGKNOW Device}

The COGKNOW device was personalized and adjusted to Alice's needs, and her responses indicated that she used some of the functions and rejected others (Table 2). Alice's general opinion of the device was that it was good, easy to understand and to learn how to use, but she stated that she was not in need of most of the functions at present. Observations indicated that she could easily manage to operate the functions that she appreciated, such as the music player, while she needed repeated instructions to understand and manage other functions such as the reminders to eat lunch, take her medicine and call friends, and using the help button and the picture dialling. Alice stated that she sometimes got nervous about having the device in her home since she was not always confident about how to operate it on her own. The device was placed in the kitchen, and neither Alice nor her partner seemed to think it was obstructing. Since Alice spent most of her day in the kitchen, she could hear the music while doing other things. The partner perceived that most functions could be useful for Alice, however she needed to be both motivated and trained 
Table 2. Overview of the Areas of Need Identified in the Second Test of the Cogknow Project, the Personalized Functions Offered by the Device Under Consideration, and the Responses to the Usage of the Device

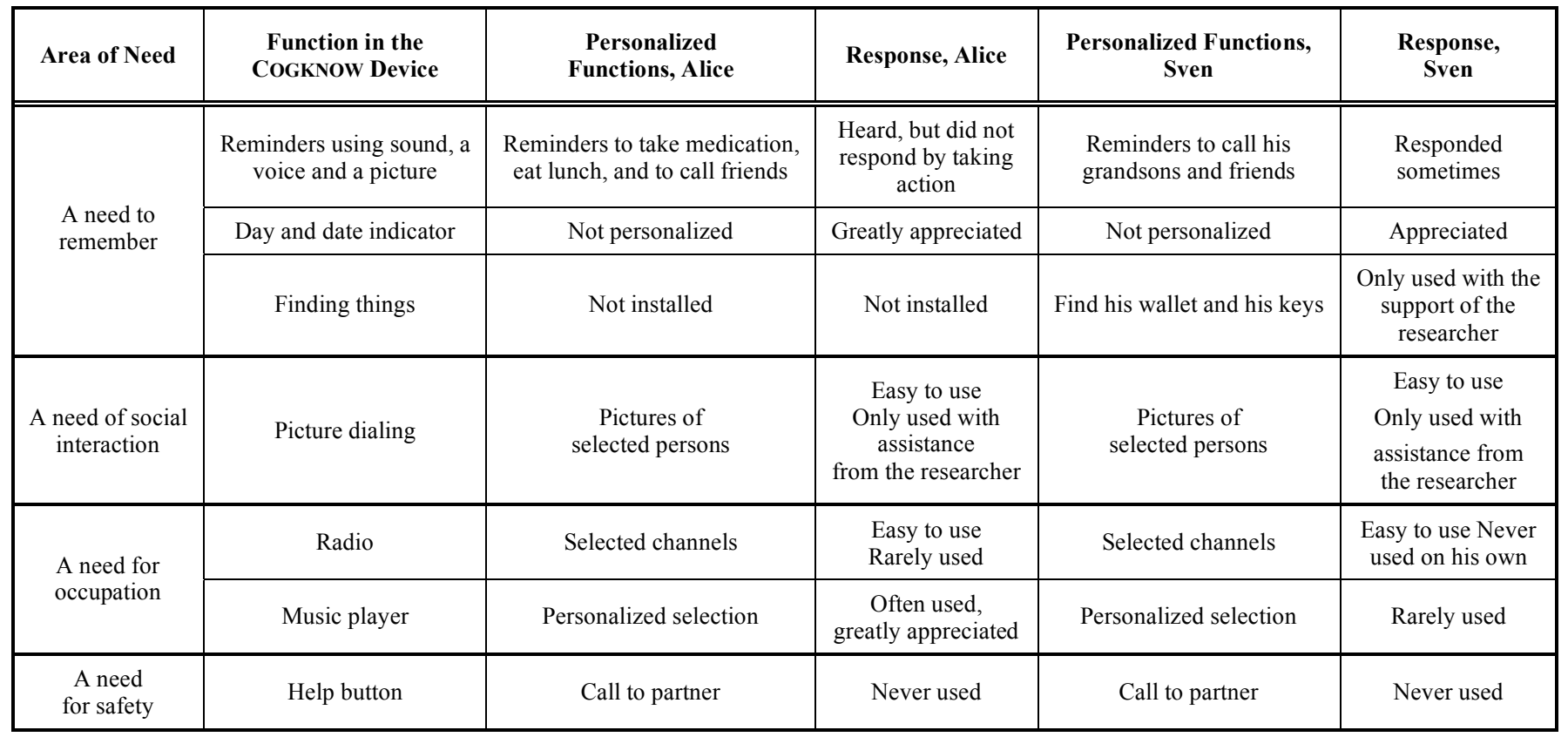

to use them through extensive support. Alice's partner was very skilled at using computers, and for several years there had been computers in their home. He found the CoGKNOW device very interesting, and saw many possibilities and useful functions in the device.

\section{Needs Associated with Alice's Daily Activities}

In several situations in Alice's daily life it was obvious that she had trouble satisfying her needs. Her need for occupation was obvious, and most of the time it could be satisfied. Her strategy to maintain control seemed to be to do things she knew she was capable of. She cleaned the house and did the laundry almost every day, and stated that "I can clean the house, even though I have Alzheimer's". She avoided things that were too complicated or involved many steps, like cooking or baking, and most of the household appliances were too difficult for her to handle. Another area that was important for her was managing common daily activities. Many of the household activities were performed by Alice's partner, such as cooking, making purchases and doing the maintenance of the house. Alice used several excuses for not doing these tasks anymore, like "Why should I do everything?" or "It is good that he does the cooking, then I don't need to". Alice's dependency on others was also apparent when visiting unknown environments, where she became totally dependent on her companion. When visiting shops to make smaller purchases, she was very determined about what to buy, but she had no notion of the value of money. Alice's need for safety became obvious when visiting less known environments, as she lost her orientation very soon, became stressed and was inattentive to traffic. Alice was a very sociable person who always enjoyed company, and therefore she had a need for social interaction. She chose to socialize with her friends' one at the time, since it seemed to be hard for her to interact with several persons at the same time. During visits from friends and relatives, the support she received from her partner helped her to cope and maintain a feeling of control. Alice had a great need for assistance remembering names. She had no problem recognizing people, but had forgotten the names of many of them. She also had a need to be reminded to eat lunch and to take her pills. She generally had problems keeping track of time and following oral and written instructions. Normally she forgot to eat anything other than breakfast during the day, and had problems remembering to take her medicine. Her partner wrote down important events in a calendar placed on the kitchen table, and she identified the year, date and day through the daily newspaper. One of the most important things for Alice was her need to be treated as usual. She was very keen to not show her memory problems and not to lose face seemed to be important to her. At several occasions she expressed anger when people tried to indicate that she did not remember something or that she could not perform certain tasks. "I get so angry and fed up when others interfere. Why do they do it"? Alice struggled with her self-image and the impact that the disease was having on her. She denied her disease or personified it. "I don't give a damn about having Alzheimer's, he does nothing..." and repeated that "Mr Alzheimer has been stopped, he can't harm me". Several times she compared herself with others, who, she said, had it worse and remembered less than her saying, for example: "I talk to myself and comfort myself knowing that others have it worse, and then it feels better".

\section{Changes in Alice's Needs 18 Months Later According to her Partner}

The need for occupation was difficult to handle for Alice because she was no longer capable of occupying herself as she had before with household activities. She watched TV during daytime, which she had never used to do before. They had talked about the possibility of visiting a day care centre, but Alice refused that option. In terms of daily activities, Alice was still able to do most things as before, but things 
took longer to perform and were not done as well as they had been before. Her dependency on her partner had increased, and she asked for more support than before when he was around. Her need for assistance to remember to perform activities also included taking showers and finding the way home. She was still performing her personal ADL, even if her partner sometimes had to remind her to take care of her personal hygiene. Alice had become unwilling to leave the house. Her partner anticipated it was because she was worried that she would not find her way home. Her decreased capability of orientation was also shown when they visited their home town. Her partner often had the impression that she had no idea where they were, even if they were in very familiar areas, which meant that her need for safety had expanded to include the familiar surroundings. When it came to Alice's need for social interaction, she still seemed to enjoy company, even though she did not speak as much as before. Her contact with her female friends remained, but she met them more rarely. She had started to be afraid of being alone and sometimes cried when her partner went to work. He was worried that this loneliness might harm her, and believed that the possibility of Alice visiting a day care centre might fulfil not only her need for occupation, but also her need for company. Alice still recognized people. Her struggle with her self-image was still as strong as before. According to her partner, she often said that the disease had not affected her since she saw her self as being capable of doing things as she had before.

\section{Sven's Story}

Sven used to work as an administrator at a large industry before his retirement, which was a job he had appreciated a great deal. He was diagnosed with Alzheimer's disease three years before being included in the study. When he became involved in the COGKNOW project he had a score of 22 out of 30 points on the MMSE [23] and was about 80 years of age. Sven and his wife had been married for over fifty years and their marriage and their relationship seemed to be characterized by mutual love and friendship. They lived in the house they had built when they were newly married, and they had a son and three grandsons living in the same town. Socializing with the family members had always been an important part of Sven's life.

\section{Testing the COGKNOW Device}

Sven had high expectations of the assistive device when he agreed to participate in the test, but he very soon became disillusioned and declared that it was not in line with his needs. He felt that it only could do simple things and did not solve his dementia related problems in the way that he had hoped. In the test, the devices were personalized to meet his needs in terms of finding his keys and wallet, listening to recorded stories and reminding him to call his grandsons and friends (Table 2). Sven perceived the reminder function to be useful, and observations showed that he responded to the reminders when he could hear them, which he was not always able to do because of his hearing problems. His partner confirmed the usability of a reminder function, and saw Sven's reminders to call his grandson's through the picture dialling function as a good opportunity for him to maintain contact with them. Sven could easily understand the date, day and time indicator, which he appreciated a greatly. The 'find thing' function was potentially useful, since he easily forgot where he had put his keys and his wallet. Despite that, however, he never used that particular function or the personalized music function. Observation showed that Sven had some difficulties in using different functions independently, and was in need of practising a considerable amount since he had difficulty learning. Sven's wife had limited experience of computers, but all through the test she supported him a prodigious amount. At the same time, it was obvious that in the eyes of Sven's wife, the device was an intrusion in the home environment: it occupied valuable workspace in the kitchen, and the cables interfered with cleaning. It also interfered with her normal routines of listening to a particular radio channel, and listening to the personalized recorded stories intended for Sven became another deviation from normal routines.

\section{Needs Associated with Sven's Daily Activities}

Sven had problems occupying himself in the home and was not used to doing household chores. He had a need for occupation indoors since his condition hampered the more demanding outdoor activities that he had done previously. He was able to cut the lawn or shovel snow in the winter, even if his partner thought the work was a bit unsatisfactory. He was able to read the newspaper, but had problems watching TV owing to hearing problems and had difficulty to following the plots. For several years Sven used to go bowling once a week with his former colleges from work, but he had now chosen to withdraw from this when, to his embarrassment, he discovered that he could no longer manage to count the points. One of his favourite occupations that he still managed to do was to take walks in a nearby recreation area. "Some days I feel sad... with this job I have [referring to the disease]... [Laughs]... then I am in the woods... and... it's like medicine to me... I think of a lot of things... both old and new..." In many ways, Sven's need for daily activities was met by his partner, on whom he was very dependent. He asked for her support as soon as she was out of sight, but at the same time he could become very irritated when she gave him instructions. His son also assisted him with the smaller repairs and maintenance work on the house.

When Sven took his regular walks in a familiar area of forest, he usually had no problem orientating himself and could easily describe every path. However, he also admitted that there were times when he had a feeling of being lost and that frightened him. His need for safety was also shown when visiting the town centre, and he sometimes had problems knowing what direction he should take. He stated that "More and more often, I don't do the larger things on my own... then I want the company of a good man or a good woman..." Sven was a very social person who enjoyed company with family and friends, and was usually able to satisfy his need for social interaction. He was open to new contacts, and explained how he appreciated it when people he met on his daily walks stayed to talk with him. He was a great story-teller and talked a good deal about the old times. The family had many friends that they used to socialise with, but socialising had decreased owing to both the disease and his hearing problems. Sven had no problem recognizing and remembering the names of those close to him, and most of the time he could name people he met in the street. However, 
the time he failed to recognize people he was very embarrassed. Sven had an obvious need of assistance to remember what day or date it was. Usually he could manage by looking at the newspaper and using a calendar to keep track of the passage of time. Sven was aware of his disease and of how it affected him, but was very keen to be treated as usual. He did his best not to expose his need for assistance when he was out of the home. He struggled with his self-image and had difficulty identifying himself with other persons with dementia, and when visiting the day care centre, he managed by taking on the role as an assistant to the staff. In interviews he often commented on his loss of skills, expressing sadness and he said "I think a lot when I am alone... I wonder what the future might bring".

\section{Changes in Sven's Needs 18 Months Later According to his Partner}

Eighteen months later, Sven was no longer capable of doing much in the home anymore, because of both the progression of the Alzheimer's disease, and also owing to the fact that his physical health had decreased. The newspaper was no longer of interest, neither was the TV nor the radio. Twice a week he visited a day care centre, which he appreciated a great deal. In that way, his need for occupation was satisfied. In addition to these visits, his days mostly consisted of doing his personal ADL, eating and sleeping. Sven's need to manage activities on his own was satisfied by receiving increased support from his partner with most of his daily activities. He could manage to eat by himself, but the food had to be prepared since he was no longer capable of peeling the potatoes or cutting meat. Sven was still anxious about his personal hygiene, and had problems dressing himself. His ability to orient himself no longer existed, even in his immediate surroundings, so his need to be in a safe environment was very obvious at this stage. The deterioration of his ability to orientate himself had forced his partner to forbid him to go outside strolling without company. Sven's interaction with friends and relatives had decreased further and was limited to his immediate family. He appreciated and was cheered up by the visits from his relatives, even if he rarely took part in the communication, and he also made regular visits to the day care centre. Both the visits from his relatives and his visits at the day care centre fulfilled Sven's need for social interaction. As far as Sven's memory was concerned, his memory had deteriorated to the extent that he had difficulty recognizing friends and many of his relatives, so he had a strong need of assistance to remember. Sometimes he forgot the faces and the names of his four grandsons, with whom he had always had a very close relationship. In his struggle to maintain his self-image, Sven was still eager not to show his limitations and the problems he had fulfilling needs. He was aware of how the disease not only affected his ability to perform daily activities, but also the impact it had on his personality.

\section{The Complex Issues Associated with Accepting the Use of a New Digital Assistive Device}

The interpretation was based on the observations of daily activities and the experiences obtained from testing the device with Alice and Sven in the second iteration of the tests conducted for the CoGKNOW project.

\section{Self-Image}

The main influence on usage seemed to be the person's self-image. Sven's perceptions of his needs and desires when personalising the COGKNOW device before the test was carried out did not correspond with his interest later on in using the device. He could identify and express specific needs he had for support, such as help finding keys and his wallet, and occupying himself. But when he discovered that the usage of the device did not eliminated his diffuse feeling of being different from before, it seemed as though he lost interest in using the specific functions of the device. Sven expressed an expectation that the device would help solve his disease-related problems. The observations made of his daily activities showed that he was very keen on maintaining an image of being competent and not affected by the disease, even though his ability to perform many daily activities had decreased. He was conscious of his cognitive problems and could explain that he felt different from before, but he could never clearly describe the problems. This effect on his selfimage, the feeling of being different, seemed real to him but at the same time was very diffuse.

Alice's perceived herself to be a competent person capable of performing her activities in daily life, and the observations revealed that she had several strategies to maintain her self-mage. At the same time her partner identified several areas where she needed support and the COGKNOW device was personalized according to those needs. This included the need to be reminded to perform daily activities and being occupied. During the test she only used the function she was sure she could manage on her own and which she also identified as corresponding to her desires. A reasonable interpretation was that she used the device in a way that matched her self-image. In the observations it was shown that she personalized the perception of the disease as Mr. Alzheimer and she tried to keep him a long distance away in her life. She often avoided things, situations and persons that could remind her of her different cognitive impairments. A possible interpretation was that the usage of the Cogknow device reminded her of her cognitive impairments, and in that way it threatened her self-image.

\section{Support from the Person's Partner}

Receiving support from the person's partner seemed to be a necessity for the usage of new devices. Both Alice and Sven had been married for a long time, and their marriages seemed to be characterized by mutual love and respect. Both Alice's and Sven's partners had a desire to make life as good as possible for them, which was also their reason for supporting Alice's and Sven's participation in the COGKNOW project.

Alice and Sven had different life situations. Alice's husband was still working and away from home during the day time. He was very interested in testing the devices and tried to support her when he was at home. The observation indicated that she could manage many of the household chores independently, but was in need of support from her husband when confronted with complicated tasks or new activities like the usage of the CoGKNOW device. During the follow up interview it was clear that the disease had progressed, which made her more dependent on her partner. 
Sven and his wife were nearly 80 years old and lived in a tight relationship, usually doing most of their daily activities together. It seemed as if the motivation for his wife to support him in using the COGKNOW device was directly related to Sven's interest in participating in the project. In the beginning she was very supportive and encouraged him to use the device, but when he lost interest her motivation to support him also faded.

\section{DISCUSSION}

The aim of this case study was to explore the complex issues involved in the process from a user-driven development to the acceptance and usage of a new digital assistive device for persons with mild dementia.

The main finding was that even if a digital assistive device is developed in a rigorous participatory process and personalized for each individual who will use it, the acceptance of the device is influenced by factors such as the person's self-image and the support received from their partner.

Already more than ten years ago research in the areas of system designing highlighted the importance of identifying needs among the prospective users [30] and the methodology of user involvement has in recent years been further discussed [31] and developed [32, 33]. The challenge in involving persons with mild dementia in a user-driven development process is described [34,35], even if there still is a need for more research in this area [36]. There are researchers arguing that people with dementia should not be involved too early in the development process since exposure to poorly functioning can bring an experience of failure, disappointment, and an unwillingness to try out fully functional devices later [37]. This risk has to be taken into account and carefully considered in relation to what results it is possible to achieve if the target group is not directly involved in the development process.

The result of this study indicates that even if there was an ambitious process of user-driven development in the COGKNOW project [9] it was apparent that some aspects of needs were not well understood. The general needs were well documented [15] but there were some challenges adjusting these general needs to a technical function suitable to personal preferences. One identified challenge is to clarify what and whose needs there are to be satisfied by a digital assistive device [38]. Another challenge in this process is to consider that persons with dementia have difficulties with abstract thinking, including perceiving how something would work if conditions or functions were to change [39], how their disease will affect them, and what needs they might have in the future. It has been shown that some of these problems can be addressed by using very concrete and task-related questions and a mixed method approach in the collection and analysis of data [34].

The result also raises the question of what level of needs there are to be supported. There is an indication that higher level of needs as self-image was important in the acceptance of the digital assistive device. This need was pronounced for Alice and Sven, and relates to Maslow's description of higher levels of needs, a need for belonging, love and self esteem. Neither their physical needs, as the need of assistance to remember to eat and take medicine, nor their need of safety seemed to be a priori to Alice and Sven, as been highlighted by other authors [6]. Thielke et al. [38] argues how the desire to preserve self-esteem can be an obstacle in the adoption of technical devices, when the person, like Alice, views themselves as not in need of help. Persons will be unlikely to adopt and use technical devices that support needs above or below the one that is relevant to them at a particular time, no matter how unobtrusive or intelligent they might be [38] This highlights the importance of developing the methods and tools for identifying needs in the development process of assistive technology for persons with mild dementia.

The importance of understanding the impact of higher level of needs [7] as maintaining a person's self-image can be understood from Sabat's $[12,40]$ interpretation of how social construction theory describes the selfhood of persons with dementia. He divides selfhood into three aspects: Self 1 is expressed as I, me, and myself, and is the self of personal identity, which has to do with the experience of being an individual and having the same point of view over time. Self 2 is the self of mental and psychical attributes, past and present. It also includes the diagnosis of probable Alzheimer's disease and the related embarrassment, depression and frustration over the loss of certain cognitive abilities together with one's desire to maintain dignity based on one's positive Self 2 attributes [12, 40]. Self 3 is the multiplicity of social identities the person constructs with the necessary cooperation of others. One can be a loving wife, a loyal friend or the 'dysfunctional patient with dementia' [12]. When looking at Alice and Sven from the perspective of Sabat's description of selfhood, both their Self 2 and Self 3 dimension of selfhood had an impact on the usage of the digital assistive device.

Alice was very keen to stress her integrity and her capability of coping with things, which can be interpreted as her having held on to her positive Self 2 attributes. Her positive Self 2 was also reinforced by her partner, who encouraged her to continue to perform household duties and other activities despite the progress of the disease. Alice's strong Self 2 gave her confidence and a belief in herself which could be the reason that she did not identify herself as being in need of an assistive device. The only function Alice used regularly was the music player, since listening to music was one her favorite occupations and it seemed to be strongly associated with her Self 2 . This can be interpreted as being as if the assistive digital device supports positive Self 2 attributes and satisfies self-identified needs, which could enhance both the desire to use the function and also facilitate the ability to learn how to use it. Functions intended to meet Alice's needs in relation to her cognitive problems, e.g. to remind her to eat lunch, seemed to strengthen her negative Self 2 and were therefore avoided. Alice's Self 3 was constructed through the close and mutual relationship with her partner and close friends who helped her to maintain a valued social identity $c f$. [40]. The use of a specially designed digital assistive device to compensate for cognitive problems did not suit her struggle to maintain a valued social identity.

Sven had an expectation that the digital assistive device would solve his cognitive problems, and when this was not fulfilled his Self 2 was negatively affected. It appeared that 
the functions of the assistive digital device did not correspond with his view of himself and he therefore lost confidence in the assistive device. Another factor that might have lowered Sven's interest in using the device was the perceived simplicity of its functions. It made him embarrassed and disappointed since it did not correspond to his expectations of an advanced digital assistive device that he could show off to friends about. Indeed, he appeared to fear that the simplicity of the functions would make his friends look upon him as a 'person with Alzheimer's' who needs an assistive device, and not the Sven they formerly knew. This seemed to constitute a major threat to Sven's social identity and his perception of himself as a sociable person, and was a threat to his Self 3. By not using the digital assistive device the Self 3 could be maintained.

The acceptance of a digital assistive device has been described by some researchers [41] as being strongly associated with the ability to maintain a certain desired selfimage, and not only a compensation for physical impairment, which the results in our study also support. Nygård [42] states that technology could encompass certain meanings which are individualized and closely incorporated with the unfolding of each participant's life story and the image of self that they present. When integrating a new digital assistive device it is a prerequisite and a fundamental issue to take into consideration that the device should support the person's self-image to get the device to be used.

\section{Methodological Considerations}

To ensure the quality of the research multiple sources of data were used [20], both from the COGKNOW test and the subsequent observations and interviews with both the persons with dementia and their partners on performance in everyday life. The goal was to get a broader description of the participants needs for the interpretation of why the digital assistive device not was used. Handling multiple sources of data can be difficult to master, but the collective experiences of the authors minimized this problem. All co-writers have been directly involved in the analysis and interpretation of the data to increase the trustworthiness in the results [43]. To reach internal validity [20] there has been recurrent discussion between the authors about the focus of the research during the whole process to discover causal links between the data and the interpretation of the results. It can be seen as a limitation that the study only involved two cases. However, the data collected was rich and collected over a long time period, which compensates this possible limitation. We assume therefore that the results achieved external validity and can be transferred to other contexts where persons with mild dementia are using a digital assistive device $c f$. [20]. In the whole process of data collection and analysis rigor has been maintained through the ongoing discussion maintained between the authors to ensure the reliability of the study.

There are several ethical and methodological aspects to consider when involving persons with dementia in research [44-46]. It is important to pay attention to the process of obtaining informed consent. For many persons with dementia participation in a research project often is seen as a social event [46] that might distract the participants from judging what participating in a research project involves.
Another aspect is to find appropriate ways to collect data, so that the information gathered represents the view of the person with dementia, and not only the opinion of their partner [47]. A strategy to overcome these problems in this study was to establish a good relationship $c f$. [44, 46] built on trust, warmth and empathy $c f$. [47]. The observations were conducted in an atmosphere of mutual enjoyment, without losing focus of the aim of the observations. This contributed to Alice's and Sven's feeling of being relaxed despite their awareness of being observed. The interviews following the observations were conducted in the homes of Alice and Sven, to ensure a familiar and relaxed environment without external disturbance. Adequate time was given so that they had the opportunity to reflect on each question at their own pace, and some questions were repeated and reformulated to ensure that they were understood [48, 49]. Special attention was given by the first author to show respect and be sensitive to their private sphere. The visits were characterized by sensitivity and responsiveness to the participant's reactions.

\section{CONCLUSIONS}

Even if persons afflicted with dementia and their partners are incorporated in the early development and the personalization of a digital assistive device, it is a process to integrate the device into daily life. The acceptance of a digital assistive device among persons with dementia can be seen as a process that begins with identifying individual needs, continuous with personalizing the functions, and the usage to which the digital assistive device can be acceptably put in the eyes of the person with dementia. Finally comes the integration of the device as a natural part of daily life. An important part of this challenging and time-consuming process is to enhance the person's self-image by support the right level of needs during the whole process. In addition, the eventual acceptance of a device requires a considerable amount of time, support and encouragement from both the partner and professionals. A useable digital assistive device, accepted by the person with dementia, that supports the selfimage has also the potential to promote a parson-centered support.

\section{ACKNOWLEDGEMENT}

This study was carried out at the Department of Health Science, Luleå University of Technology as a part of the COGKNOW project, which was funded under the Information and Society Technologies (IST) program under the Sixth Framework Programme (FP 6) of the European Union. We would like to thank Alice and Sven and their partners for their cooperation in this study.

\section{CONFLICT OF INTEREST}

None declared.

\section{REFERENCES}

[1] Hagen I, Cahill S, Macijauskiene J, Nygård AM, Faulkner JP. Technology in dementia care. Technol Disabil 2007; 19: 55-60.

[2] Edvardsson D, Winblad B, Sandman PO. Person-centred care of people with severe Alzheimer's disease: current status and ways forward. Lancet Neurolog 2008; 7: 362-7.

[3] Edvardsson D, Fetherstonhaugh D, Nay R. Promoting a continuation of self and normality: person-centred care as described by people with dementia, their family members and aged care staff. J Clin Nurs 2010; 19: 2611-8. 
[4] Astell JA. Technology and personhood in dementia care. Qual Aging 2006; 7(1): 15-25.

[5] Fortin J. Human needs and nursing theory. In: Kim Hesook S, Kollak I, Ed. Nursing theories: Conceptual and philosophical Foundation $2^{\text {nd }}$ ed. New York, NY, USA: Springer Publishing Company. 2005; pp. 10-26.

[6] Scholzel-Dorenbos CJM, Meeuwsen EJ, Olde Rickert MG. Integrating unmet needs into dementia health-related quality of life research and care: introduction of the hierarchy model of needs in dementia. Aging Ment Health 2010; 14(1): 113-9.

[7] Maslow AH. A theory of human motivation. Psychol Rev 1943; 50(4): 370-96.

[8] Lauriks S, Reinersmann A, Van der Roest HG, et al. Review of ICT-based services for identified unmet needs in people with dementia. Aging Res Rev 6 2007; 223-46.

[9] Davies RJ, Nugent CD, Donelly MP, et al. A user driven approach to develop a cognitive prosthetic to address the unmet needs of people with mild dementia. Pervasive and Mobile Computing 2009; 253-67.

[10] Donelly M, Nugent C, McLean S, et al. A mobile multimedia technology to aid those with Alzheimer's disease. IEEE Multimedia 2010, April-June.

[11] Kitwood T. Dementia reconsidered. Great Britain: Biddles limited, Guildford and Kings Lynn 1997.

[12] Sabat S R. Capacity for decision-making in Alzheimer's disease: selfhood, positioning and semiotic people. Aust N Z J Psychiatry 2005; 39: 1030-5.

[13] Östlund B, Topo P. Conclusions: Time to get involved! In: Topo P, Östlund B, Ed. Dementia, Design and Technology. IOS Amsterdam, Press; 2009; pp. 141-6.

[14] Bossen AL, Pringle Specht JK, and McKenzie SE. Needs of people with early-stage Alzheimer's disease. J Gerontol Nurs 2009; 35(3): $8-15$.

[15] van der Roest H, Meiland FJM, Comijs HC, et al. What do community-dwelling people with dementia need? A survey of those who are known to care and welfare services. Int Psychogeriatr 2009; 21(5): 949-65.

[16] Castillo CM, Woods B, Orrell M. People with dementia living alone: what are their needs and what kind of support are they receiving? Int Psychogeriatr 2010; 22(4): 607-17.

[17] Johnston D, Samus QM, Morrison A, et al. Identification of community-residing individuals with dementia and their unmet needs for care. Int J Geriatr Psychiatry 2011; 26: 292-8.

[18] van der Roest H, Meiland FJM, Maroccini R, Comijs HC, Jonker C, Dröes RM. Subjective needs of people with dementia: a review of the literature. Int Psychogeriatr 2007; 19(3): 559-92.

[19] Meiland FM, Reinersmann A, Bergvall-Kåreborn B, et al. COGKNOW: Development of an ICT device to support people with dementia. JITH 2007; 5(5): 324-34.

[20] Yin RK. Case study research. Designs and methods. California: Sage Publications, Inc. 2009.

[21] Casey D, Houghton C. Clarifying case study research: examples from practice. Nurse Res 2010; 17(3): 41-51.

[22] Anthony S, Jack S. Qualitative case study methodology in nursing research: an integrative review. J Adv Nurs 2009; 65(6): 1171-81.

[23] Folstein MF, Folstein SE, McHugh PR. Mini-mental state. A practical method for grading the cognitive state of patients for the clinician. J Psychiatr Res 1975; 12(3): 189-98.

[24] Quinn PM. Qualitative Research \& Evaluations Methods. $3^{\text {rd }}$ ed. California: Sage Publications, Inc. 2002.

[25] Häggström T, Jansson L, Norberg A. Skilled carers' ways of understanding people with Alzheimer's disease. Sch Inq Nurs Pract 1998; 12(3): 239-66.

[26] Nygård L. How can we get access to the experience of people with dementia? Scand J Occup Ther 2006; 13: 101-12.
[27] McKillop J, Wilkinson H. Make it easy on your self! Advice to researchers from someone with dementia being interviewed. Dementia 2004; 3(2): 117-25.

[28] Krippendorf K. Content Analysis. An introduction to its methodology. Sage publications: Thousands Oaks 2004.

[29] Graneheim UH, Lundman B. Qualitative content analysis in nursing research: concepts, procedures and measures to achieve trustworthiness. Nurse Educ Today 2004; 24(2): 105-12.

[30] Patniak D, Becker R. Needfinding: The why and how of uncovering people's need. Des Manag J 1999; 10(2): 37-43.

[31] Olphert W, Damodaran L. Citizen participation and engagement in the design of e-government services: The missing link between effective ICT design and delivery. JAIS 2007; 8(9): 491-507.

[32] Bergvall-Kåreborn B, Howcroft D, Ståhlbröst A, Wikman MA Participation in living lab: Designing systems with users. In: PriesHeje J, Veneble JJ, Bunker D, Russo NL, DeGross J, Eds. IS Design Science Research, IFIP AICT 318; 2010; pp. 317-26.

[33] Bergvall-Kåreborn B, Ståhlbröst A. User expressions translated into requirements. Hum Tech 2010; 6(2): $212-29$.

[34] Orpwood R, Sixsmith A, Torrington J, Chadd J, Gibson G, Chalfont G. Designing technology to support quality of life of people with dementia. Technol Disabil 2007; 19: 103-12.

[35] Sävenstedt S, Meiland FJM, Karlsson E, Moelaert F, Dröes RM. The effectiveness of a mixed method design in evaluating the userfriendliness and usefulness of assistive technology for people with mild dementia. Dementia; Accepted.

[36] Topo P. Technology studies to meet the needs of people with dementia and their caregivers. A literature review. J Appl Gerontol 2009; 28(1): 5-37.

[37] Orpwood, R. Involving people with dementia in the design process - Examples of iterative design. In: Topo P, Östlund B, Eds. Dementia, Design and Technology. IOS Amsterdam, Press; 2009; pp. 79-95.

[38] Thielke S, Harniss M, Thompson H, Patel S, Demiris G, Johnson $\mathrm{K}$. Maslow's hierarchy of human needs and the adoption of healthrelated technologies for older adults. Ageing Int 2011. DOI. 10. 1007/s12126-001-9121-4

[39] Nygård L. Living with dementia and the challenges of domestic technology. In: Topo P, Östlund B, Eds. Dementia, Design and Technology. IOS Amsterdam, Press; 2009; pp. 9-25.

[40] Sabat SR. The experience of Alzheimer's disease. Life trough a tangled veil. Oxford: Blackwell Publisher, Ltd. 2001.

[41] Larsson LM, Nygård L. Incorporating or resisting assistive devices: Different approaches to achieve a desired occupational self-image. OTJR 2003; 23(2): 67-75.

[42] Nygård L. The meaning of everyday technology as experienced by people who live alone. Dementia 2008; 7(4): 481-502.

[43] Schwandt TA. Dictionary of qualitative inquiry. $2^{\text {nd }}$ ed. California: Sage Publications, Inc. 2001.

[44] Hellström I, Nolan M, Nordenfeldt L, Lundh, U. Ethical and methodological issues in interviewing persons with dementia. Nurs Ethics 2007; 14(5): 609-19.

[45] Sherratt C, Soteriou T, Evans S. Ethical issues in social research involving people with dementia. Dementia 2007; 6(4): 463-79.

[46] Rauhala M. Ethical councelling as a working method in designing technology for people with dementia. In: Topo P, Östlund B, Ed. Dementia, Design and Technology. IOS Amsterdam, Press; 2009; pp. 97-110.

[47] Froggatt A. Self-awareness in early dementia. In: Gearing B, Johnsson M, Heller I. Ed. Mental health problems in old age. Buckingham: Open University Press, 1988: 131-6.

[48] McKillop J, Wilkinson H. Make it easy on yourself! Advice to researchers from someone with dementia being interviewed. Dementia 2004; 3(2): 117-25.

[49] Beuscher L, Grando V. Challenges in conducting qualitative research with individuals with dementia. Res Gerontol Nurs 2009; 2(1): 6-11. 